Jurnal Matematika UNAND

Vol. VIII No. 1 Hal. 150 - 156

Edisi Mei 2019

ISSN : 2303-291X

(C)Jurusan Matematika FMIPA UNAND

\title{
TEOREMA SYLOW
}

\author{
KHOBERLIN, I MADE ARNAWA, NOVA NOLIZA BAKAR \\ Program Studi S1 Matematika, \\ Fakultas Matematika dan Ilmu Pengetahuan Alam, Universitas Andalas, \\ Kampus UNAND Limau Manis Padang, Indonesia. \\ email : khoberlin146@gmail.com
}

Diterima 9 Maret 2019 Direvisi 7 April 2019 Dipublikasikan 7 Mei 2019

\begin{abstract}
Abstrak. Tulisan ini membahas tentang Teorema Sylow. Misalkan $G$ suatu grup dengan orde hingga, $v$ suatu bilangan bulat positif, dan $v$ membagi orde dari $G$, yang akan dibahas adalah syarat cukup agar $G$ memuat subgrup dengan orde $v$.

Kata Kunci: Grup, Orde, Subgrub, Teorema Sylow.
\end{abstract}

\section{Pendahuluan}

Teorema Lagrange memiliki hubungan dengan orde dalam grup hingga. Teorema Lagrange menyatakan bahwa jika $G$ suatu grup hingga dan $H$ subgrup dari $G$, maka orde dari $H$ harus membagi orde dari $G$. Converse teorema Lagrange dalam teorema Cauchy oleh Augustin Louis Cauchy [4] dan teorema Sylow oleh matematikawan Norwegia Ludwig Sylow pada tahun 1872 [2], jika suatu bialangan bulat positif $v$ membagi orde dari grup hingga $G$, maka dijamin ada $H$ subgrup dari $G$ dengan orde $v$.

\section{Landasan Teori}

\subsection{Teori Himpunan}

Definisi 2.1. [5] Misalkan $A$ dan $B$ suatu himpunan. Himpunan $A$ dan $B$ saling lepas jika dan hanya jika $A \cap B=\varnothing$.

Definisi 2.2. [3] Misalkan A dan B suatu himpunan.

(1) Perkalian kartesian $A \times B$ didefinisikan sebagai himpunan $A \times B=\{(a, b) \mid$ $a \in A, b \in B\}$.

(2) Setiap subset dari $A \times B$ disebut sebagai relasi dari $A$ ke $B$.

(3) Relasi dari $A$ ke $A$ disebut sebagai relasi di $A$ (pada A).

Definisi 2.3. [1] Misalkan A suatu himpunan dan $\sim$ suatu relasi pada $A$. Relasi $\sim$ disebut sebagai relasi ekuivalen pada A, jika: 
(1) Refleksi, jika setiap $a \in A$ berlaku $a \sim a$,

(2) Simetri, jika setiap $a, b \in A$ dengan $a \sim b$ berlaku $b \sim a$,

(3) Transitif, jika setiap $a, b, c \in A$ dengan $a \sim b$ dan $b \sim c$ berlaku $a \sim c$.

Definisi 2.4. [3] Misalkan $X$ suatu himpunan yang tak kosong dan $\sim$ suatu relasi ekuivalen pada $X$. Untuk setiap $a \in X$, didefinisikan kelas ekuivalen dari a sebagai $c l(a)=\{x \in X \mid x \sim a\}$ yaitu kelas ekuivalen dari a yang memuat semua anggota $X$, yang terkait dengan a pada relasi $\sim$.

Teorema 2.5. [3] Misalkan $X$ suatu himpunan yang tak kosong dan $\sim$ suatu relasi ekuivalen pada $X$, maka untuk setiap $a, b \in X$ berlaku:

(1) $c l(a) \neq \varnothing$,

(2) Berlaku hanya salah satu dari $c l(a) \cap c l(b)=\varnothing$ atau $c l(a)=\operatorname{cl}($ b) yaitu dua kelas ekuivalen yang berlaku hanya salah satu dari berikut sama atau tidak mempunyai elemen,

(3) $X=\bigcup_{a \in X} c l(a)$.

Definisi 2.6. [3] Misalkan $X$ suatu himpunan yang tidak kosong. Himpunan $K$ adalah himpunan dari subset-subset yang tak kosong dari $X$ sedemikian sehingga setiap dua anggota dari $K$ yang berbeda saling lepas, maka $K$ disebut sebagai partisi dari $X$, jika $X$ sama dengan hasil gabungan atau union dari semua anggota $K$.

Akibat 2.7. [3] Misalkan X suatu himpunan yang tak kosong dengan suatu relasi ekuivalen yang didefinisikan pada X, maka himpunan semua kelas-kelas ekuivalen di $X$ merupakan partisi dari $X$.

\subsection{Pemetaan}

Definisi 2.8. [3] Misalkan A dan B suatu himpunan yang tak kosong. Relasi $f$ dari $A$ ke $B$ disebut sebagai pemetaan atau fungsi $f$ dari $A$ ke $B$ dan ditulis sebagai $f: A \longrightarrow B$ jika untuk setiap $a \in A$ dengan tepat satu $b \in B$ sedemikin sehingga $(a, b) \in f$ (b disebut sebagai peta atau image dari a pada $f$ yang ditulis sebagai $b=f(a)$ dan a disebut sebagai prapeta atau pre-image dari b pada $f$ ). Himpunan $A$ disebut sebagai domain dari $f$ dan $B$ disebut sebagai kodomain dari $f$. Subset dari $B$ yang memuat hanya anggota-anggota dari $B$ yang mempunyai pre-image di $A$ disebut sebagai range dari $f$.

Definisi 2.9. [4] Misalkan A dan B suatu himpunan.

(1) Pemetaan $f: A \longrightarrow B$ dikatakan pemetaan satu-satu atau pemetaan injektif jika setiap $a_{1}, a_{2} \in A$ dengan $f\left(a_{1}\right)=f\left(a_{2}\right)$, maka $a_{1}=a_{2}$ (atau jika setiap $a_{1}, a_{2} \in A$ dengan $a_{1} \neq a_{2}$, maka $\left.f\left(a_{1}\right) \neq f\left(a_{2}\right)\right)$.

(2) Pemetaan $f: A \longrightarrow B$ dikatakan pemetaan pada atau pemetaan surjektif jika untuk setiap $b \in B$, terdapat $a \in A$ sedemikian sehingga $f(a)=b$. 


\subsection{Bilangan Bulat}

Definisi 2.10. [3] Misalkan a suatu bilangan bulat tak nol. Bilangan a dikatakan membagi bilangan bulat $b$ ditulis sebagai $a \mid b$, jika $b=a c$ untuk suatu bilangan bulat c.

Definisi 2.11. [3] Misalkan p suatu bilangan bulat dan $p>1$. Bilangan $p$ disebut sebagai bilangan prima jika hanya 1 dan $p$ yang membagi $p$.

\subsection{Grup}

Definisi 2.12. [5] Misalkan $G$ suatu himpunan yang tak kosong. Pemetaan dari $G \times G$ ke $G$ disebut operasi biner pada $G$.

Definisi 2.13. [1] Misalkan G suatu himpunan tak kosong dan * suatu operasi biner yang didefinisikan di $G$. Unsur-unsur di $G$ dikatakan membentuk grup terhadap operasi * jika memenuhi:

(1) Untuk setiap $a, b \in G$ berlaku $a * b \in G$ ( $G$ bersifat tertutup terhadap operasi *),

(2) Untuk setiap a,b,c $\in G$ berlaku $a *(b * c)=(a * b) * c$ ( $G$ bersifat asosiatif terhadap operasi $*$ ),

(3) Terdapat suatu unsur di $G$ yang dilambangkan dengan e sehingga untuk setiap $a \in G$ berlaku $a * e=e * a=a$ ( $G$ memiliki unsur identitas terhadap operasi *),

(4) Untuk setiap $a \in G$, ada suatu unsur di $G$ yang dilambangkan dengan $a^{-1}$ sehingga berlaku $a * a^{-1}=a^{-1} * a=e$ (setiap unsur di $G$ mempunyai invers terhadap operasi $*$ ).

Catatan:

(1) Untuk selanjutnya $a * b$ ditulis sebagai $a$ b.

(2) Jika setiap unsur di $G$ membentuk grup terhadap operasi biner di $G$, maka $G$ suatu grup.

Definisi 2.14. [3] Misalkan $G$ suatu grup. Banyaknya unsur pada grup $G$ disebut orde dari $G$ dan dinotasikan sebagai o $(G)$ atau $|G|$.

Lema 2.15. [3] Misalkan G suatu grup, maka:

(1) Elemen identitas di $G$ tunggal,

(2) Invers dari setiap $a \in G$ tunggal,

(3) $\left(a^{-1}\right)^{-1}=a$ untuk setiap $a \in G$, dimana $a^{-1}$ merupakan invers dari a di $G$,

(4) $(a b)^{-1}=b^{-1} a^{-1}$ untuk setiap $a, b \in G$,

(5)(a) Jika $a b=a c$, maka $b=c$ untuk setiap $a, b, c \in G$,

(b) Jika $b a=c a$, maka $b=c$ untuk setiap $a, b, c \in G$. 


\subsection{Subgrup}

Definisi 2.16. [3] Misalkan $G$ suatu grup dan $H$ subset yang tak kosong dari $G$. Himpunan $H$ disebut subgrup dari $G$ jika $H$ membentuk grup terhadap operasi biner di $G$.

Teorema 2.17. [5] Misalkan $G$ suatu grup dan $H$ subgrup dari $G$. Unsur identitas di $H$ sama dengan unsur identitas di $G$.

Teorema 2.18. [3] Misalkan $G$ suatu grup dan $H$ subset yang tak kosong dari $G$. Himpunan $H$ disebut subgrup dari $G$ jika dan hanya jika

(1) Untuk setiap $a, b \in H$ berlaku $a b \in H$,

(2) Untuk setiap $a \in H$ berlaku $a^{-1} \in H$.

Definisi 2.19. [3] Misalkan $G$ suatu grup dan $H$ subgrup dari G. Untuk setiap $a, b \in G$, a dikatakan kongruen dengan $b \bmod H$ ditulis sebagai $a \cong b \bmod H$ jika $a b^{-1} \in H$.

Teorema 2.20. [3] Misalkan $G$ suatu grup, $H$ subgrup dari $G$, dan $a, b \in G$. Didefinisikan relasi kongruen modulo $H$ sebagai berikut $a \cong b \bmod H$ jika $a b^{-1} \in$ $H$. Relasi kongruen modulo $H$ adalah suatu relasi ekuivalen di $G$.

Definisi 2.21. [3] Misalkan $G$ suatu grup dan $H$ subgrup dari $G$ dan relasi kongruen modulo $H$ suatu relasi ekuivalen pada $G$. Untuk setiap $a \in G$ didefinisikan kelas ekuivalen dari a sebagai himpunan

$$
\operatorname{cl}(a)=\{x \in G \mid x \cong a \bmod H\} .
$$

Definisi 2.22. [3] Misalkan $G$ suatu grup, $H$ subgrup dari $G$, dan $a \in G$.

(1) Himpunan $\mathrm{Ha}=\{h a \mid h \in H\}$ disebut koset kanan dari $H$ di $G$.

(2) Himpunan $a H=\{a h \mid h \in H\}$ disebut koset kiri dari $H$ di $G$.

Teorema 2.23. [3] Misalkan $G$ suatu grup, $H$ subgrup dari $G$, dan a $\in G$, maka $H a=\{x \in G \mid x \cong a \bmod H\}=\operatorname{cl}(a)$.

Akibat 2.24. [3] Misalkan $G$ suatu grup dan $H$ subgrup dari $G$, maka untuk setiap $a, b \in G$ berlaku:

(1) $H a \neq \varnothing$,

(2) Berlaku hanya salah satu dari $\mathrm{Ha} \cap \mathrm{Hb}=\varnothing$ atau $\mathrm{Ha}=\mathrm{Hb}$ yaitu dua kelas ekuivalen yang berlaku hanya salah satu dari berikut sama atau tidak mempunyai elemen,

(3) $G=\bigcup_{a \in G} H a$.

Teorema 2.25. [3] Misalkan $G$ suatu grup hingga dan $H$ subgrup dari $G$, maka $o(H)$ membagi $o(G)$.

Lema 2.26. [1] Misalkan $G$ suatu grup dan $H$ subgrup dari $G$. Terdapat korespondensi satu-satu antara setiap dua buah koset kanan dari $H$ di $G$.

Teorema 2.27. [3] Misalkan $G$ suatu grup, $H$ subgrup dari $G$, dan $a, b \in G$, maka: 
(1) (a) $H a=H$ jika dan hanya jika $a \in H$;

(b) $a H=H$ jika dan hanya jika $a \in H$,

(2) (a) $H a=H b$ jika dan hanya jika a $b^{-1} \in H$;

(b) $a H=b H$ jika dan hanya jika $a^{-1} b \in H$.

\section{Teorema Sylow}

\subsection{Teorema Sylow Pertama}

Teorema 3.1. [2] Misalkan $G$ suatu grup hingga, $p$ suatu bilangan prima, dan $p^{\alpha}$ membagi orde dari $G$, maka $G$ memuat subgrup dengan orde $p^{\alpha}$.

Bukti. Misalkan $G$ suatu grup hingga, $p$ suatu bilangan prima dan $p^{\alpha}$ membagi orde dari $G$, akan ditunjukkan $G$ memuat subgrup dengan orde $p^{\alpha}$. Untuk menunjukkan $G$ memuat subgrup dengan orde $p^{\alpha}$, dilakukan langkah-langkah pembuktian sebagai berikut:

(1) Penjelasan combinatorial, yaitu:

(a) Menunjukkan bahwa terdapat $s$ sehingga $p^{s} \mid\left(p^{\alpha}-k\right)$ dan $p^{s} \mid$ $\left(p^{\alpha} m-k\right)$ untuk setiap $k=1,2, \cdots, p^{\alpha}-1$,

(b) Menunjukkan bahwa terdapat $r$ sehingga $p^{r} \mid\left(\begin{array}{c}p^{\alpha} m \\ p^{\alpha}\end{array}\right)$ dan $p^{r} \mid m$.

(2) Pembentukan $H$ subgrup dari $G$, yaitu:

(a) Menjelaskan adanya $H$,

(b) Menunjukkan bahwa $H$ subgrup dari $G$.

(3) Pembuktian orde dari $H$ adalah $p^{\alpha}$, yaitu:

(a) Menunjukkan bahwa $p^{\alpha} \leq o(H)$,

(b) Menunjukkan bahwa $o(H) \leq p^{\alpha}$.

Contoh 3.2. Himpunan $K$ suatu grup berorde 12600 atau $o(K)=12600$. Oleh karena $12600=2^{3} 3^{2} 5^{4} 7$, maka $o(K)=2^{3} 3^{2} 5^{4}$ 7. Berdasarkan Teorema 3.1 diperoleh $K$ mempunyai paling sedikit satu subgrup yang berorde $1,2,2^{2}, 2^{3}, 3,3^{2}, 5,5^{2}, 5^{3}, 5^{4}$, atau 7 . Ada kemungkinan terdapat subgrup dari $K$ yang berorde selain dari $1,2,2^{2}, 2^{3}, 3,3^{2}, 5,5^{2}, 5^{3}, 5^{4}$, dan 7 , namun Teorema Sylow tidak menjamin adanya subgrup tersebut.

\subsection{Sylow p-subgrup}

Definisi 3.3. [3] Misalkan $G$ suatu grup hingga, $p$ suatu bilangan prima, dan $n$ suatu bilangan bulat tak negatif. $p^{n}$ membagi orde dari $G$ dan $p^{n+1}$ tidak membagi orde dari $G$, maka $H$ subgrup dari $G$ sedemikian sehingga $o(H)=p^{n}$ disebut Sylow p-subgrup dari $G$.

Contoh 3.4. Himpunan $Z_{12}=\{\overline{0}, \overline{1}, \overline{2}, \overline{3}, \overline{4}, \overline{5}, \overline{6}, \overline{7}, \overline{8}, \overline{9}, \overline{10}, \overline{11}\}$ suatu himpunan bilangan bulat modulo 12. Didefinisikan penjumlahan modulo $12\left(+_{12}\right)$ di $Z_{12}$ sebagai berikut $\bar{a}+{ }_{12} \bar{b}=\bar{c}$ dimana $c$ adalah sisa dari $a+b$ setelah dibagi 12. Berdasarkan 
Definisi 2.14, Orde dari $Z_{12}$ atau $o\left(Z_{12}\right)$ adalah 12. Himpunan $A=\{\overline{0}, \overline{2}, \overline{4}, \overline{6}, \overline{8}, \overline{10}\}$ subgrup dari $Z_{12}$. Berdasarkan Definisi 2.14, Orde dari $A$ atau $o(A)$ adalah 6. 6 tidak dapat dibentuk dalam perpangkatan bilangan prima, maka $A$ bukan Sylow p-subgrup dari $Z_{12}$. Himpunan $B=\{\overline{0}, \overline{3}, \overline{6}, \overline{9}\}$ subgrup dari $Z_{12}$. Berdasarkan Definisi 2.14, Orde dari $B$ atau $o(B)$ adalah $4.4=2^{2}$ dapat dibentuk dalam perpangkatan bilangan prima, $2^{2} \mid o\left(Z_{12}\right)$, dan $2^{2+1} \nmid o\left(Z_{12}\right)$, maka $B$ merupakan Sylow p-subgrup dari $Z_{12}$. Himpunan $C=\{\overline{0}, \overline{4}, \overline{8}\}$ subgrup dari $Z_{12}$. Berdasarkan Definisi 2.14, Orde dari $C$ atau $o(C)$ adalah 3. $3=3^{1}$ dapat dibentuk dalam perpangkatan bilangan prima, $3^{1} \mid o\left(Z_{12}\right)$, dan $3^{1+1} \nmid o\left(Z_{12}\right)$, maka $C$ merupakan Sylow p-subgrup dari $Z_{12}$.

Akibat 3.5. [3] Misalkan $G$ suatu grup hingga. Jika $p$ suatu bilangan prima sedemikian sehingga $p^{n} \mid o(G)$ dan $p^{n+1} \nmid o(G)$, maka ada Sylow p-subgrup dari $G$.

Bukti. Misalkan $G$ suatu grup hingga, $p$ suatu bilangan prima, $p^{n} \mid o(G)$ dan $p^{n+1} \nmid o(G)$. Berdasarkan Definisi 3.3 dan Teorema 3.1 diperoleh ada Sylow psubgrup dari $G$.

\section{Kesimpulan}

(1) Misalkan $G$ suatu grup hingga dan $p$ suatu bilangan prima. Jika $p^{\alpha} \mid o(G)$, maka ada $H$ subgrup dari $G$ sedemikian sehingga $o(H)=p^{\alpha}$.

(2) Misalkan $G$ suatu grup hingga, $p$ suatu bilangan prima, dan $n$ suatu bilangan bulat tak negatif. $p^{n}$ membagi orde dari $G$ dan $p^{n+1}$ tidak membagi orde dari $G$, maka $H$ subgrup dari $G$ sedemikian sehingga $o(H)=p^{n}$ disebut Sylow p-Subgrup dari $G$.

(3) Misalkan $G$ suatu grup hingga. Jika $p$ suatu bilangan prima sedemikian sehingga $p^{n} \mid o(G)$ dan $p^{n}+1 \nmid o(G)$, maka ada Sylow p-subgrup dari $G$.

\section{Ucapan Terima kasih}

Penulis mengucapkan terima kasih kepada Bapak Dr. Mahdhivan Syafwan, Ibu Dr. Yanita, dan Ibu Izzati Rahmi HG, M.Si yang telah memberikan masukan dan saran dalam penyempurnaan penulisan artikel ini.

\section{Daftar Pustaka}

[1] Heirstein, I.N. 1975. Topic in Algebra; edisi ke-2. John Wiley and Sons, New York

[2] Kammuller, F. dan L.C. Paulson. 1999. A Formal proof of Sylow's theorem. Journal of Automated Reasoning. 23: 235 - 265

[3] Khanna, V.K. dan S.K. Bhambri. 1993. A Course in Abstract Algebra. Vikas Publishing House PVT LTD, New Delhi

[4] Meo, M. 2004. The Mathematical Life of Cauchy's Group Theorem. Historia Mathematica. 31: 196 - 221

[5] Morris, D.W. dan J. Morris. 2013. Proofs and Concepts The Fundamental of Abstract Mathematics. University of Lethbridge, New York 
156 Khoberlin dkk

[6] Raisinghania, M.D. dan R.S. Aggarwal. 1980. Modern Algebra; edisi ke-1. S. Chand and Company LTD, New Delhi 